\title{
Conical Fluidized Bed with Arc Design for Improved Performance of Gas
} Distributor

\author{
Ihsan Hamawand ${ }^{1}$, W. P. da Silva ${ }^{2}$, Ali H. Jawad ${ }^{3}$ \\ ${ }^{1}$ National Centre for Engineering in Agriculture, University of Southern Queensland, QLD 4350, Australia \\ ${ }^{2}$ Federal University of Campina Grande, Paraíba, Brazil \\ ${ }^{3}$ Material Engineering, University of Technology, IRAQ \\ Corresponding: Ihsan Hamawand, NCEA, University of Southern Queensland, Building P9, West Street, 4350 \\ Toowoomba, QLD, phone: +61-7-4631 2531, Australia
}

Received: April 3, 2015 Accepted: April 18, 2015 Online Published: May 21, 2015

doi:10.11114/set.v2i1.836

URL: http://dx.doi.org/10.11114/set.v2i1.836

\begin{abstract}
Particles distributions along a conical fluidized bed were predicted by an alternative arrangement of the minimum fluidization velocity equation. The proposed approach introduces two new equations which present the particle diameter in the bed as function of: height in the bed $(Z)$, angle of inclination of the fluidized bed wall $(\theta)$, input flow rate $\left(Q_{o}\right)$, and gas distributor diameter $\left(D_{0}, 2 r_{0}\right)$. A novel arc-shaped design of the gas distributor was suggested, which provides enhanced distribution of the gas and enables greater control on the direction of the gas inlet. The model showed that the inclination of the fluidized bed wall should not exceed a critical angle, which can be determined with the set of equations specially developed for this purpose, to prevent inhomogeneous fluidization across the bed and accumulation of particles along the walls.

By applying the Box Wilson Method, theoretical data were obtained for constant column diameter at the base $(0.05 \mathrm{~m})$, and varying bed height, $\mathrm{Z}$, (range: 0.5 to $1.5 \mathrm{~m}$ ), velocity of gas inlet, $\mathrm{U}$, (range 0.25 to $1 \mathrm{~m} \mathrm{~s}^{-1}$ ), and balance factor, a, (range: 0.5 to 1 , a new factor), respectively. The angle of inclination of the wall was first predicted based on the above parameters, and subsequently, the particle size distribution along the column was determined. Theoretically the novel arc-shaped distributor design has shown the potential of generating homogeneous fluidization regimes along the bed.
\end{abstract}

Keywords: conical distributor design, fluidized bed, particle distribution, particle size, particle trajectory

\section{Introduction}

Fluidized bed (FB) has been under research for a long time, and it has been used for various industries because of the high mixing and contact surface area between the particles and the fluidization fluid, which lead to high mass and heat transfer (Janvijitsakul \& Kuprianov, 2008). The variety of fluidized beds encountered in commercial operation is enormous and includes powders having mean sizes as small as $15 \mu \mathrm{m}$ and large as $6 \mathrm{~mm}$, bed diameters from 0.1 to $10 \mathrm{~m}$, bed depths from a few centimeters to $10 \mathrm{~m}$ and gas velocities from 0.01 to $3 \mathrm{~m} / \mathrm{s}$ or even as high as $10 \mathrm{~m} / \mathrm{s}$ for recirculating high velocity beds. The behavior of particulate solid in fluidized beds depends largely on a combination of their mean particle size and density, and it has become increasingly common to discuss fluidized systems in relation to the so-called Geldart fluidization (Ihsan Hamawand, 2004, Ihsan Hamawand, 2009). The minimum fluidization velocity is very important parameter in a fluidized bed process; it depends directly to the weight of the particle, where it increases with increase in particle weight. When gas is passed upwards through a packed bed unrestrained at its upper surface, the pressure drop increases with gas velocity until, on the microscopic scale, the drag on an individual particle exceeds the force exerted by gravity or, on the macroscopic scale, the pressure drop across the bed equals the weight of the bed per unit area (Ihsan Hamawand, 2004).

One of the FB design is the conical fluidized bed, introduced in industries like combustion of biomass to produce energy (Janvijitsakul and Kuprianov, 2008; Kuprianov et al., 2006; Kuprianov et al., 2005; Permchart and Kuprianov, 2004), and agglomeration of particles in pharmaceutical application to modify their physical properties, size, shape, density and porosity (Jimenez et al., 2006; Wormsbecker et al., 2005, 2009; Chaplin et al., 2005). Conelike bunks have been connected broadly in different procedures, for example, the covering, drying and granulation of particulate materials and immobilized wastewater treatment and microorganism forms. In a cone shaped couch, where the cross area increment with the cot tallness, higher speed is kept up at the lower piece of the segment, making it conceivable to 
fluidize particles of wide size disseminations. Toyohara and Kawamura (1992) demonstrated that particles in a taped gas-solids fluidized couch circled in the middle of center and the annulus area in a very nearly consummately blended state, which helped advance blending. Many of the Drying technology using conical shape FB, found that when the granule is initially very wet, the flow of fluidizing gas centralized (Pugsley et al., 2007). After this period, data shows that as the granule dried the centralized gas flow breaks apart and particle mixing improve this likely associate with higher rate of drying. The behavior of particle inside the conical FB are studied by (Wiens and Pugsley, 2006), where the dense particle region are gathered near the wall of the FB with decreasing solid concentration toward the center. For high moisture content there is a presence of centralized core bubble in the bed and more uniform fluidization through the bed cross section towards the end of the drying process (Chaplin et al., 2004).

Many literatures studied the hydrodynamic characteristics of the conical bed with three different cone angles, the results show that there are fixed bed, partially fluidized and spouting bed regime (Shan et al., 2000, 2001). The other kind of conical bed is the conical spouted bed, where it is used in pyrolysis of plastic and tire waste, it gives the same patterns of the fluidization regions (Wang et al., 2006; Olazar et al., 2006; Aguado et al., 2005; Olazar et al., 1995). In regards to the gas distributer, a flat plate distributor design is studied by (Son et al., 2006), to show its effect on the behavior of fluidization at the fully fluidized region.

The hydrodynamic characteristics in conical bed with flat plate distributor and different cone angle were studied and modeled to show their effect on the fluidization velocity (Kaewklum and Kuprianov, 2008; Biswal et al., 1985). In spite of the widely used conical fluidized bed, its hydrodynamic properties are not fully understood. In this theoretical study a conical gas distributer was applied, where its design is very depending on the angle of the conical FB. The direction of the holes in the distributor is set parallel to the FB wall inclination. Some papers studied the conical fluidized bed with conical distributor which is roughly stands for ash-agglomerating fluidized bed coal gasifier (Cao et al., 2008; Bi and Kojima, 1996; et al., 1997).

A few studies have endeavored to anticipate the base fluidization speed of both gas-robust and fluid strong decreased fluidized bunks by joining the cone shaped geometry into the base fluidization speed comparison. Zhou et al. (2009) changed for the forecast of Umf in a three-stage tapered fluidized couch by representing the geometrical variety of the cone shaped bunk. It is observed that the adjusted Tune et al. model gave a superior assention than the changed Zhang et al. model in examination with the current exploratory information. Dora et al. (2013) decided the hydrodynamic qualities of fluidization in a tapered couch incorporate the base fluidization speed, cot variance, and bunk extension degrees. The reliance of these amounts on a normal molecule measurement, mass division of the fines in the mixture, introductory static cot tallness, and cone edge is examined. Jernej et al. (2014) proposed a new histogram method for the detection of minimum velocity for a fully fluidized bed, the method is statistically oriented. The histogram method uses measured data, i.e., bed pressure drop versus fluidization velocity. The minimum velocity of full fluidization is determined as the inferior fluidization velocity of the most frequent pressure drop over the fluidized bed. With this method, occasional pressure jumps around the minimum fluidization velocity were distinguished from the pressure fluctuations. The histogram method was developed on the basis of experimental results.

The novelty of this theoretical study is the arc shaped-design of the gas distributor, this will allow a homogenous distribution of the fluidization gas across the bed (radially). This may eliminate dead or particle accumulation zones as in the case of flat plate distributor. To get such result, an accurate design for the distributor must take place with a sufficient thickness. This will allow a range of minimum fluidization velocity along the vertical axis of the fluidized bed. This will allow the dried particle at the bottom of the FB to migrate to higher level as they loss more moisture.

\section{Objective}

The objective of this study is to investigate the performance of a novel conical fluidized bed, which has an arc-shaped gas distributor. A theoretical model was specially developed for this case, which enables determining the critical angle of inclination of the wall and the design of the arc-shaped gas distributor. It was hypothesized that such design will allow for greater uniformity of gas distribution within the conical bed, both radially and vertically. Compared with the commonly used flat-plate distributor design, it has a potential to produce more complete fluidization within the entire bed with significantly less dead zones.

\section{Theory}

\subsection{Hydrodynamics Theory}

This theory is based on the fact that the initial velocity at the base of the conical vessel changes in the vertical direction due to the change in the bed's diameter. This provides a wide range of velocities within the vessel. At each level of the bed, the gas velocity represents a minimum fluidization velocity for a specific size range of particles. As a result, particles are distributed along the conical vessel depending on their diameters. The equation given by Wen and $\mathrm{Yu}(1966)$ for the calculation of minimum fluidization velocity for a range of particles' diameters is as following; 


$$
U_{m f}=\frac{\mu}{\rho_{f} d_{v}}\left\{(1,135.7+0.0408 A r)^{1 / 2}-33.7\right\}
$$

Where:

$$
A r=\frac{\rho_{g} d_{v}^{3}\left(\rho_{p}-\rho_{g}\right) g}{\mu^{2}}
$$

Based on Geldart and Abrahamsen (1980), equation (1) can be used for particle diameter larger than $100 \mu \mathrm{m}$, groups B and D solids. For particles smaller than $100 \mu \mathrm{m}$ in diameter, minimum fluidization is given by Baeyens' equation (Singh and Roy, 2005):

$$
U_{m f}=\frac{\left(\rho_{p}-\rho_{g}\right)^{0.934} g^{0.934} d_{p}^{1.8}}{1,111 \mu^{0.87} \rho_{g}^{0.066}}
$$

\subsection{Vertical Distribution of Particles}

For a conical vessel (Figure 1) with angle of inclination $(\theta)$, height $(Z)$, bottom inlet radius $\left(\mathrm{r}_{0}\right)$, the diameter of the vessel at different heights is given by equation 4 ;

$$
D_{i}=2\left(r_{o}+K\right)
$$

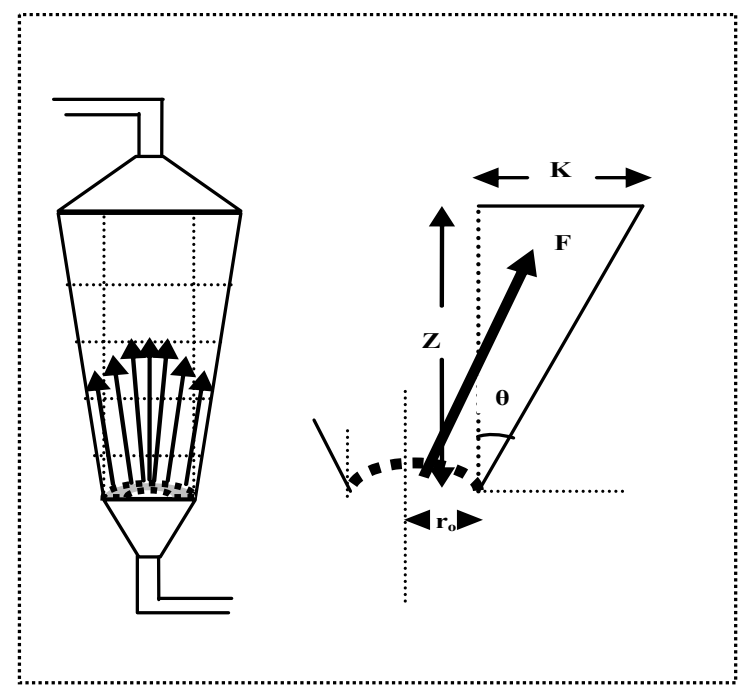

Figure 1. Description of a conical vessel and design parameters.

Where $\mathrm{K}$ is the increase in radius of the conical vessel with increasing height, $\mathrm{K}$ can be calculated from the following equations:

$$
\tan \theta=\frac{K}{Z}
$$

And,

$$
K=Z \tan \theta
$$

By substituting equation (5) in (4), the variable diameter of the vessel can be calculated as below:

$$
D_{i}=2\left(r_{0}+Z \tan \theta\right)
$$


Given, $\quad C_{1}=\frac{\left(\rho_{p}-\rho_{g}\right)^{0.934} g^{0.934}}{1,111 \mu^{0.87} \rho_{g}^{0.066}} \quad$ and substituting it in Equation (3),

The particles' diameters can be presented as dependent variable as in equation 8 ;

$$
d_{p i}=\left[\frac{U_{m f}}{C_{1}}\right]^{1 / 1.8}
$$

The system of equations given below ( 9 and 10) and (11 and 12) describe the mass flow between two points in the conical vessel (Figure 2), namely, the entrance with diameter $\mathrm{D}_{\mathrm{o}}$, and any point along the column where diameter is $\mathrm{D}_{\mathrm{i}}$;

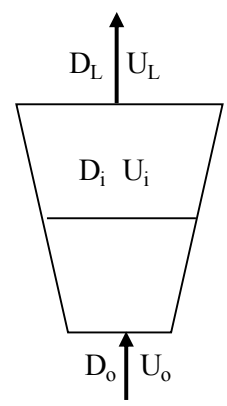

Figure 2. Graphical representation of the mass balance.

$$
\rho_{o} U_{o} \frac{\pi}{4} D_{o}^{2}=\rho_{i} U_{i} \frac{\pi}{4} D_{i}^{2}
$$

When:

$$
\rho_{0}=\rho_{i}
$$

Also,

$$
U_{i}=\frac{4 \pi D_{o}^{2}}{4 \pi D_{i}^{2}} \times U_{o}=\frac{4 Q_{o}}{\pi D_{i}^{2}}
$$

Where:

$$
Q_{o}=\frac{\pi}{4} D_{o}^{2} U_{o}
$$

Since gas velocity changes in the vertical direction according to the change in the cross sectional area of the conical vessel, then at any given height $(Z)$, the minimum fluidization velocity is determined for specific particle diameters and specific fluidization velocity ( $U_{i}=U_{m f l}$ ) by equation 11 . Substitution of equation (11) in equation (8) yields:

$$
d_{p i}=\left[\frac{4 Q_{o}}{\pi C_{1} D_{i}^{2}}\right]^{1 / 1.8}
$$

Also, substitution of equation (7) in (13) yields: 


$$
d_{p i}=\left[\frac{Q_{o}}{\pi C_{1}\left(r_{o}+Z \tan \theta\right)^{2}}\right]^{1 / 1.8}
$$

Equation (14) provides material particle diameter as a function of the location of the particle (height) in the bed and the angle of inclination of the FB wall, for particle sizes smaller than $100 \mu \mathrm{m}$.

For spherical or near-spherical materials (sphericity $\geq 0.8$ ), $d_{v}$ is given by equation (15), as follows:

$$
d_{v}=1.13 d_{p i}
$$

Now for particle size greater than $100 \mu \mathrm{m}$, by substituting equation (15) in (1) and solving for $\mathrm{d}_{\mathrm{pi}}$, it results in:

$$
d_{p i}=\frac{\mu}{1.13 \rho_{g} U_{m f}}\left\{(1,135.7+0.0408 A r)^{1 / 2}-33.7\right\}
$$

Also, substitute equation (11) in (16), gives:

$$
d_{p i}=\frac{\pi \mu D_{i}^{2}}{4.52 \rho_{g} Q_{o}}\left\{(1,135.7+0.0408 A r)^{1 / 2}-33.7\right\}
$$

Given,

$$
C_{2}=\frac{\rho_{g}(1.13)^{3}\left(\rho_{p}-\rho_{g}\right) g}{\mu^{2}}
$$

Now, subsequently, substitute equations (2), (7) and (18) in (17), yields:

$$
d_{p i}=\frac{4 \pi \mu\left(r_{o}+Z \tan \theta\right)^{2}}{4.52 \rho_{g} Q_{o}}\left\{\left(1,135.7+0.0408 \times\left(C_{2}\right)^{3}\left(d_{p i}\right)^{3}\right)^{1 / 2}-33.7\right\}
$$

Equation (19) provides the solution for particles with diameters greater than $100 \mu \mathrm{m}$. A convenient method to solve this equation is by trial and error since the independent variable $\left(\mathrm{d}_{\mathrm{pi}}\right)$ cannot be isolated.

The gas flow rate $\left(\mathrm{Q}_{0}\right)$ must be approximately equivalent to the minimum fluidization velocity for the largest particle diameter present in the solid mixture to avoid accumulation of particles at the bottom of the bed. Due to the conical section, bed diameter increases from the bottom to the top of the bed and therefore the velocity of the gas inlet decreases accordingly. At each point along the conical vessel, this velocity represents a minimum fluidization velocity for a given particle diameter. The particles move upward as they dry and lose weight. An important practical consideration for the distributor's design is that the thickness of the wall should be sufficient to provide the required direction to the fluid inlet.

\subsection{Angle of Inclination}

Based on a force balance applied on a single particle, as shown in Figure 3, and in order to enable the particles to remain away from the walls and avoid dead zones in the conical vessel, it is required for the force in the horizontal direction is less than the force in the vertical direction $(F \sin \theta<F \cos \theta)$. 


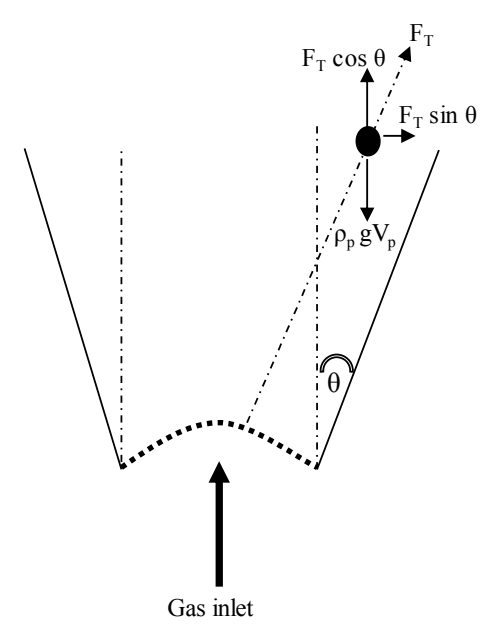

Figure 3. Graphical representation of the force balance.

The equations for the bouncy and the drag forces on a single particle are as following;

$$
\begin{gathered}
F_{B}=\frac{\pi}{6} \rho_{g} g d_{p i}^{3} \\
F_{D}=\frac{\pi}{8} C_{D} \rho_{g} d_{p i}^{2} U_{g}^{2}
\end{gathered}
$$

Where $U_{g}$ is the relative velocity between the gas and the particle. Therefore, the total force balance on a single particle is as follows:

$$
F_{T}=F_{B}+F_{D}=\frac{\pi}{24} \rho_{g} d_{p i}^{3}\left[4 g+3 C_{D} \frac{U_{g}^{2}}{d_{p i}}\right]
$$

The force exerted on the particle by the gas is a combination of two components, the vertical force (gravity);

$$
F_{T} \cos \theta=\rho_{p} g V_{p}=\frac{\pi}{6} \rho_{p} g d_{p i}^{3}
$$

And the horizontal force;

$$
F_{T} \sin \theta=\frac{\pi}{24} \rho_{g} d_{p i}^{3}\left[4 g+3 C_{D} \frac{U_{g}^{2}}{d_{p i}}\right] \sin \theta
$$

Let assume a new variable (a), where: $0 \leq \mathrm{a} \leq 1$, which is defined as below;

$$
a=\frac{F_{T} \sin \theta}{F_{T} \cos \theta-\frac{\pi}{6} \rho_{p} g d_{p i}^{3}}
$$

Then solve equation 25 for the horizontal component;

$$
F_{T} a \cos \theta=\frac{\pi}{6} a \rho_{p} g d_{p i}^{3}+F_{T} \sin \theta
$$

To enable for fluidization to take place, and at the same time it vector force in the vertical direction to be higher than that in the horizontal direction, the velocity of the gas at the inlet for a such particle size at such height most be larger than the minimum fluidization velocity. Substitute equation 24 in equation 26 and solve for $(a \cos \theta-\sin \theta)$; 
Where $d_{\text {pi }}$ is given by equation 14 :

$$
[a \cos \theta-\sin \theta]=\frac{\left[\frac{4 a \rho_{p} g}{\rho_{g}}\right]}{\left[4 g+3 C_{D} \frac{U_{o}^{2}}{d_{p i}}\right]}
$$

$$
d_{p i}=\left[\frac{\frac{\pi}{4} D_{o}^{2} U_{o}}{\pi C_{1}\left(r_{o}+Z \tan \theta\right)^{2}}\right]^{1 / 1.8}
$$

Equation (27) can be solved by trial and error to obtain the suitable wall angle $(\theta)$ for particles diameters smaller than $100 \mu \mathrm{m}$, where $\mathrm{Z}$ is the height of the conical vessel and 'a' can be assumed to be between 0 and 1 . By applying equations (19) and (27), the solution can be obtained for particle diameters larger than $100 \mu \mathrm{m}$, which needs to be done by trial and error for both $\mathrm{d}_{\mathrm{pi}}$ and $\theta$. The angle of the wall in the conical vessel will therefore be between $0^{\circ}$ and $45^{\circ}$.

3.4 Boundary Conditions for the Angle

When $a=1$, then $\theta=45^{\circ}$; therefore:

$F_{T} \cos \theta-\frac{\pi}{6} \rho_{p} g d_{p i}^{3}=F_{T} \sin \theta$

When $a=0$, the shape of the column is cylindrical; therefore:

$F_{T} \sin \theta=0$, and $\theta=0^{\circ}$,

When $a=1$, and $\theta=0^{\circ}$; therefore:

$F_{T} \cos \theta-\frac{\pi}{6} \rho_{p} g d_{p i}^{3}=0$

\section{Design of Distributor}

The proposed distributor in Figure 4 consists of an arc which its design is dependent on the bottom radius of the conical vessel and the angle of inclination of the column wall. The thickness of the distributor's wall needs to be sufficient to provide the required direction to the gas through the column.

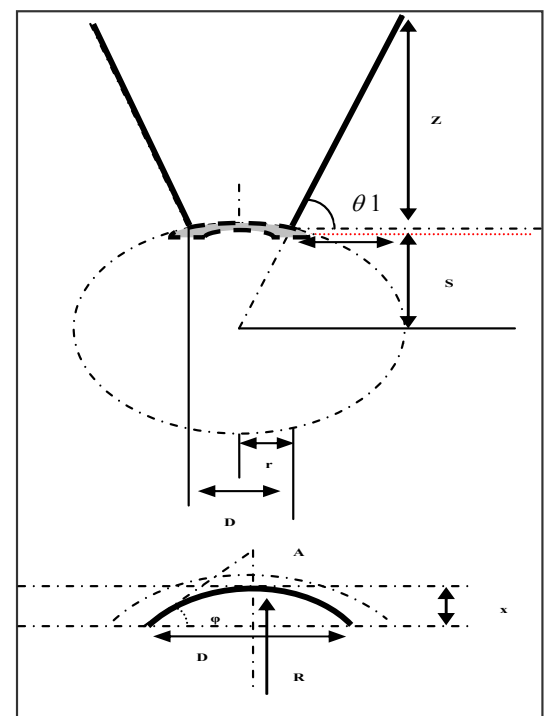

Figure 4. Specifications for the design of the proposed arc-shaped distributor. 
For a fixed radius of the conical vessel and height, the angle of inclination can be obtained from equation (27). The radius of the distributor is given by equation (28), and the length of the arc is given by equation (29).

$$
R=\frac{r}{\sin \theta}
$$

$$
A=R \times 2 \theta
$$

The other two important design parameters are the height of the arc-shaped distributor determined at the center of the conical vessel and the angle of the tangent at the end point, which can be obtained by solving equations (28) and (29), respectively.

$$
\begin{aligned}
& x=R-\frac{D}{2 \tan \theta} \\
& \varphi=\tan ^{-1}\left(\frac{2 x}{D}\right)
\end{aligned}
$$

The system of equations given above (26 to 29) will enable for optimum determination of design parameters and it confirms the importance of the angle of inclination of the wall in optimizing such design.

\section{Results and Discussions}

Particle diameters and balance factor were obtained by solving Equations (14) and (25), respectively. The angle of the conical fluidized bed was obtained by means of trial and error for fixed values of gas inlet velocities, base diameter of conical vessel, column height and balance factor. Subsequently, the angle thereby obtained was used for calculation of particle diameter's gradient along the bed. The angle of the wall represents the optimum angle at which full fluidization over the entire conical vessel occurs. Figures 5(a and b) shows the relationship between the relative position of particles in the conical vessel in relation to their diameter depending on the angle of the wall $(\theta)$ for fixed values of the balance factor $(\mathrm{a}=0.61$ and 0.89$)$ and gas velocity $\left(\mathrm{U}=0.41\right.$ and $\left.0.84 \mathrm{~m} \mathrm{~s}^{-1}\right)$. As a result, the required height $(\mathrm{Z})$ changes from $0.7 \mathrm{~m}$ in the former to $1.3 \mathrm{~m}$ in the latter. In addition, it can be seen that increase the height of the bed allows for greater angle of inclination; for example, for $\mathrm{a}=0.61$ and $\mathrm{U}=0.84 \mathrm{~m} \mathrm{~s}^{-1}, \theta$ values are $0.1 \mathrm{rad}$ for $\mathrm{Z}=0.7 \mathrm{~m}$ and $0.18 \mathrm{rad}$ for $\mathrm{Z}$ $=1.3 \mathrm{~m}$, which is explained by the space generated at higher angles enabling for more uniform particle distribution in the conical vessel. Particle distribution uniformity is at its optimum when the angle of inclination is between 0.33 and $0.37 \mathrm{rad}$, and the velocity of the gas inlet is between 0.84 and $1.0 \mathrm{~m} \mathrm{~s}^{-1}$. This result is explained by the increase in the upward force due to higher velocity of the gas enabling for uniform velocity gradient within the column in the vertical direction. Figure 6 shows that an increase in the balance factor from 0.5 to 1.0 results in increased angle of inclination (from $\theta=0.05 \mathrm{rad}$ to $\theta=0.16 \mathrm{rad}$, respectively) when $U$ is maintained constant at $0.63 \mathrm{~m} \mathrm{~s}^{-1}$. This means that with higher vertical force exerted on the particle, which is the situation with balance factor of 0.5 , the column needs to approach a cylindrical shape (constant diameter). As the balance factor approaches a maximum value of 1.0, the force exerted on the particle in the vertical direction equates the horizontal force, which still produces a homogenous fluidization. As can be seen in figure 5( $\mathrm{a}$ and $\mathrm{b}$ ), when the bed wall angle is around 0.2 and 0.37 rad there is a better distribution of the different size particles along the bed. This is due to the creation of different fluidization velocities along the bed. Higher diameter particles fluidize close to the bottom of the bed due to higher gas velocity (smaller bed diameter) and smaller diameter particles fluidize close to the top of the bed due to lower gas velocity (larger bed diameter). Similar trend in figure 6 , as the bed wall angle increases, there is a better distribution of the particles along the bed. 


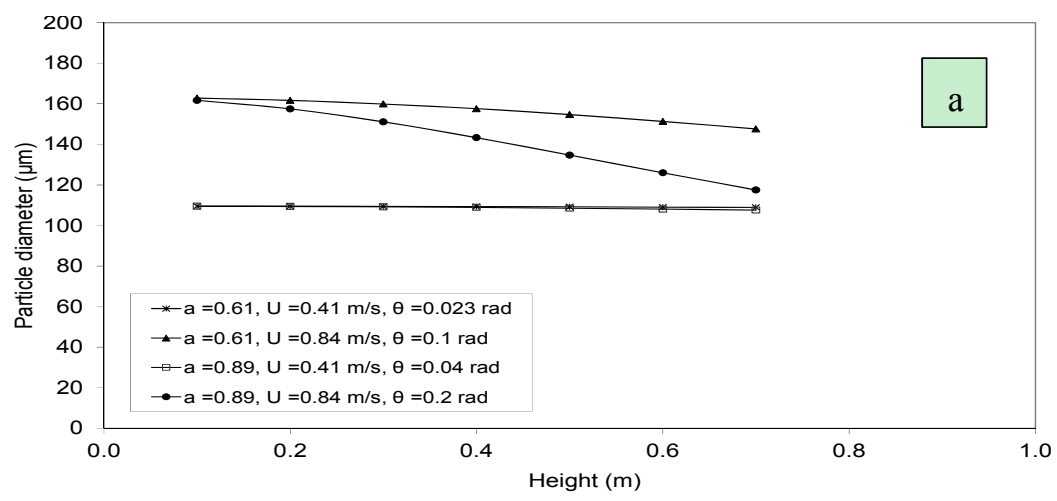

Figure 5 (a). Relationship between the relative positions of particles in the conical vessel with their diameter.

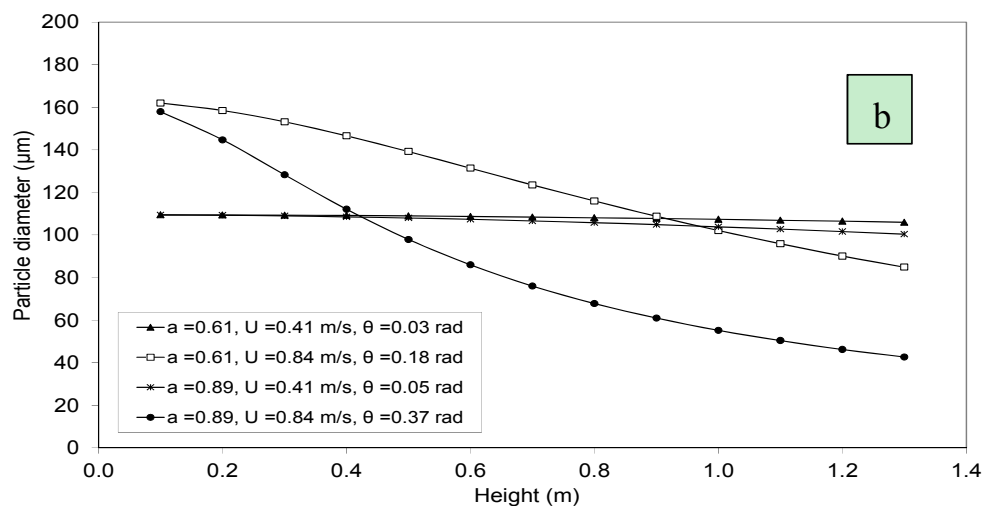

Figure 5 (b). Relationship between the relative positions of particles in the conical vessel with their diameter.

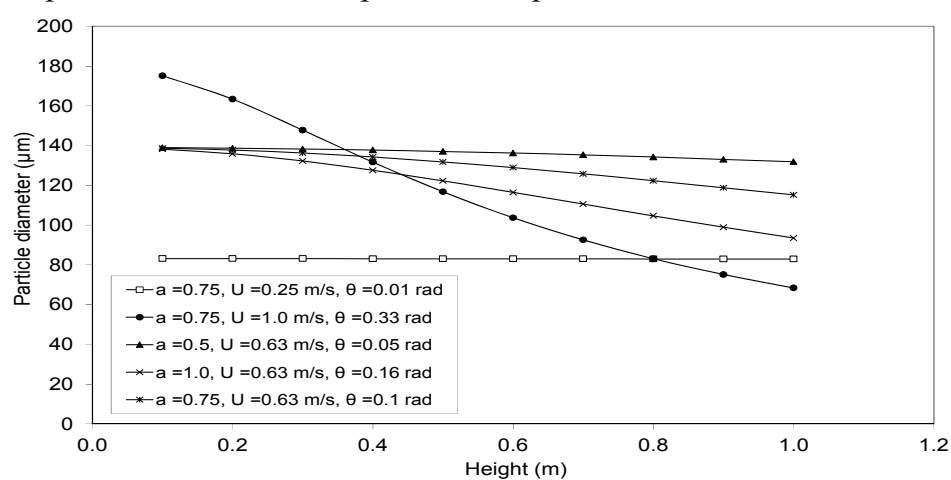

Figure 6. Relationship between the relative positions of particles in the conical vessel with their diameter.

Figures 7 to 9 were produced for a constant value of the balance factor (a) to examine the influence of gas velocity and bed height on the design of the conical bed. Figure 7 shows that there is little effect of bed height on angle of inclination $(\theta)$ since an increase in bed height from 0.7 to $1.3 \mathrm{~m}$ required an increase in $\theta$ from 0.023 to 0.03 rad. For the same increase in bed height but for using a gas inlet velocity of $0.84 \mathrm{~m} \mathrm{~s}^{-1}$, the effect of bed height is more pronounced, which requires an increase in $\theta$ from 0.1 to 0.18 , respectively. Providing the inlet gas velocity is sufficiently high to produce a homogenous fluidization, this response can be explained by the fact that an increase in bed height provides larger space and therefore enables for better particle distribution within the conical vessel. Figure 8 shows that a balance factor of 0.75 , which is a reasonable value of 'a' to ensure particles remain away from the wall of the conical vessel, produces relatively poor particle distribution along the bed, except when velocity $1 \mathrm{~m} \mathrm{~s}^{-1}$ or higher. This observation confirms that gas inlet velocity is the main factor influencing the degree of inclination of the bed walls. The trends in both figures 7 and 8 that show better distribution of the particles are those which compensate higher bed (above $1 \mathrm{~m}$ ), higher velocity (above $1 \mathrm{~m} / \mathrm{s}$ ) and higher angle of inclination (above $0.18 \mathrm{rad}$ ). It is obvious that higher angle of inclination of the bed walls can create a better distribution of the particles. But this happens only at sufficient height of the bed and gas inlet velocity. These variables have an interaction relationship where the balance factor is balancing the values of these 
variables.

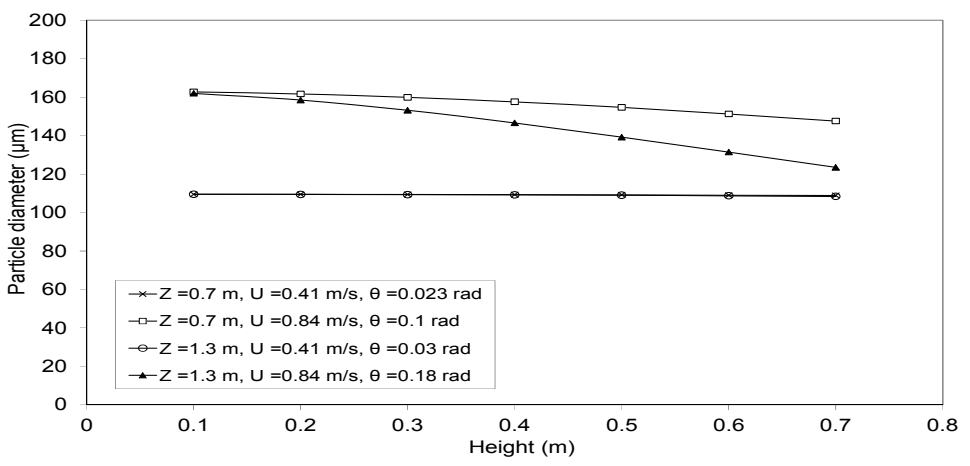

Figure 7. The influence of gas velocity and bed height on the design of the conical bed, $a=0.61$.

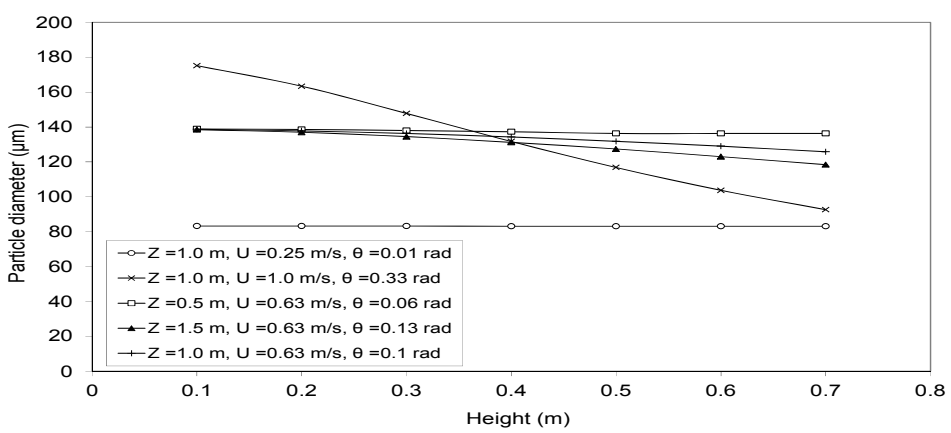

Figure 8 . The influence of gas velocity and bed height on the design of the conical bed, $a=0.75$.

Figures 9 to 11 show particle size distribution as affected by balance factor (a) and height of the bed (Z) at three different gas inlet velocities (range: $0.41,0.63$ and $0.84 \mathrm{~m} \mathrm{~s}^{-1}$ ). The angle of inclination, furthermore the particle distribution (PD) is poorly effected by the change in all variables, as shown in figure $(9$, and 10) for low gas inlet velocity $0.41 \mathrm{~m} / \mathrm{s}$ and $0.63 \mathrm{~m} / \mathrm{s}$, which is prove the majority effect of the gas inlet velocity on the wall inclination and the PD. Figure 11 shows that at high inlet velocity $\left(0.84 \mathrm{~m} \mathrm{~s}^{-1}\right)$, a bed height of $1.3 \mathrm{~m}$ provides a relatively more uniform particle distribution compared with the bed at a height of $0.7 \mathrm{~m}$ when the balance factor is 0.89 . These results highlight the interaction effect between the three variables $(U, Z$, and a) considered in this analysis. The enhanced particle distribution achieved at the corresponding highest values of bed height and balance factor tested in this study is because an increase in ' $a$ ' leads to a reduction in the force needed to produce homogeneous fluidization of particles, and increased gas inlet velocity results in relatively higher forces exerted in the column, which improve particle distribution within the column.

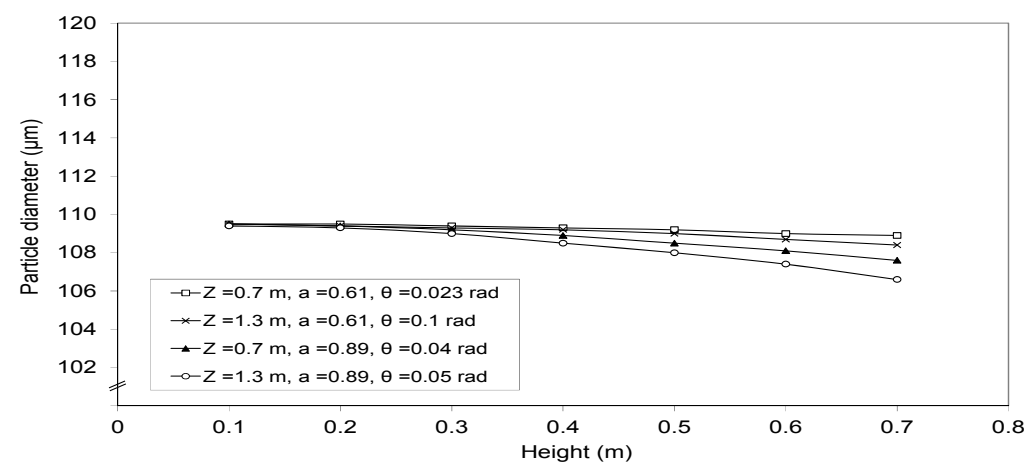

Figure 9. Particle size distribution as affected by balance factor (a) and height of the bed (Z) at gas inlet velocity 0.41 $\mathrm{m} / \mathrm{s}$. 


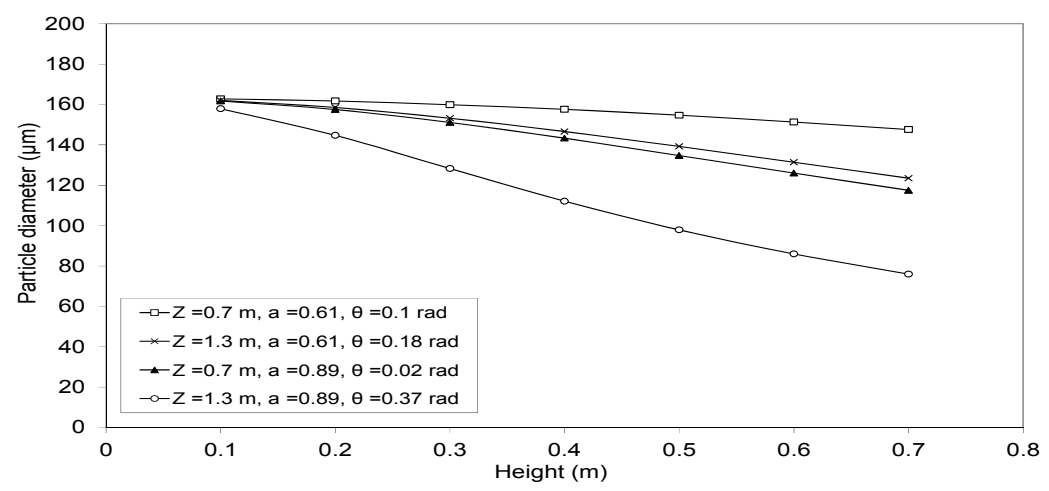

Figure 10. Particle size distribution as affected by balance factor (a) and height of the bed (Z) at gas inlet velocity 0.63 $\mathrm{m} / \mathrm{s}$.

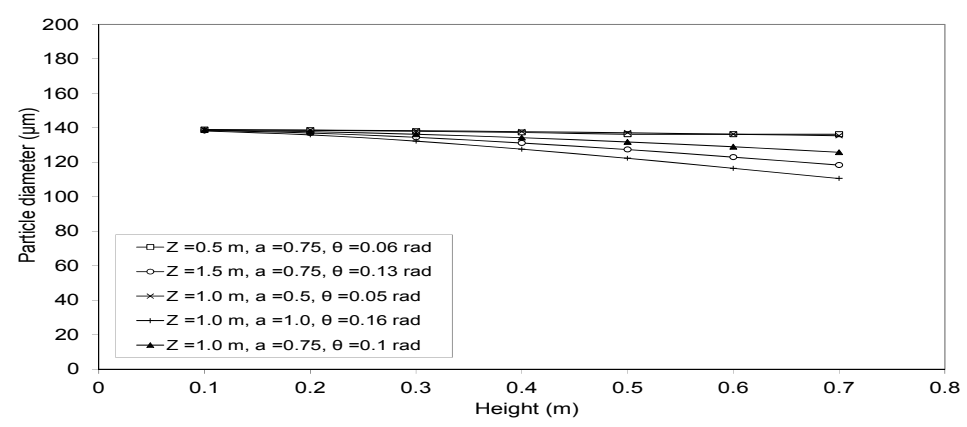

Figure 11. Particle size distribution as affected by balance factor (a) and height of the bed ( $\mathrm{Z}$ ) at gas inlet velocity 0.84 $\mathrm{m} / \mathrm{s}$.

Figure 12 shows the combined effects of the three variables (U, Z, and a) on the required inclination of the conical fluidized bed wall. When the balance factor is maintained at 0.75 and the gas inlet velocity is set at $0.63 \mathrm{~m} \mathrm{~s}^{-1}$, there is a small increase in the required bed inclination with increasing bed height from $0.2 \mathrm{~m}$ to $1.5 \mathrm{~m}$. However, a change in the balance factor (from a $=0.2$ to $\mathrm{a}=1.5$ ) at a constant bed height of $1 \mathrm{~m}$ and constant gas inlet velocity of $0.63 \mathrm{~m} \mathrm{~s}^{-1}$, show better effect on the inclination of the bed walls. The bed angle of inclination can be increased from around 0.0 rad to 0.3 rad. However, the angle of the bed wall is significantly more sensitive to changes in gas inlet velocity, as indicated by the response obtained for the wall angle of inclination $(\theta)$, when the balance factor is maintained at 0.75 and bed height at $1 \mathrm{~m}$. The angle of the bed wall increase from around $0.0 \mathrm{rad}$ at $0.23 \mathrm{~m} / \mathrm{s}$ to $0.8 \mathrm{rad}$ around $1.5 \mathrm{~m} / \mathrm{s}$ gas velocity.

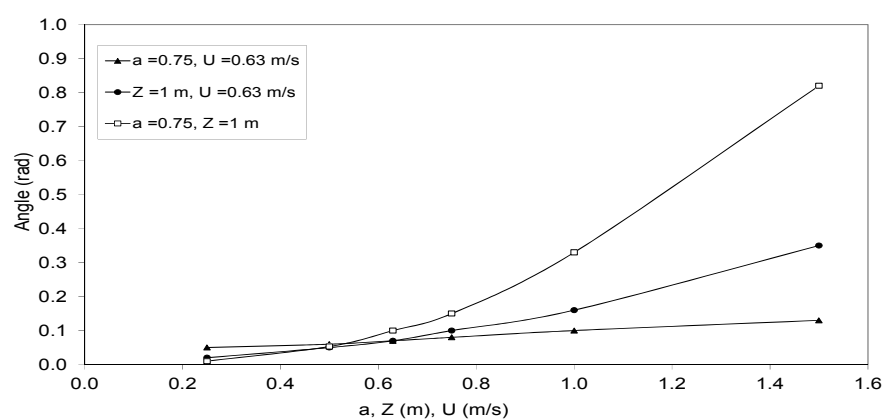

Figure 12. Determination of the angle of inclination $(\theta)$ as a function of the balance factor (a), height $(Z)$ and velocity (U).

\section{Summary}

The arc shape of the distributor was selected and designed to distribute the inlet gas at the same inclination of the bed walls. This means that the gas inlet is introduced to the bed with an angle of inclination. The difference between a conical fluidized bed with flat and an arc shaped distributor is the elimination of dead zones. Dead zones happen in conical fluidized beds with flat distributors at the area where the gas does not reach (the zone out of the area of the distributor). The parameters selected in this research have direct impact on the performance of the fluidized bed with the arc shape distributor. Gas velocity and angle have impact on the drag force and bouncy force acting on the particles in 
the bed. The angle of inclination of the bed walls is dependent on the arc shaped distributor. This angle cannot exceed a specific value due to gravity force. The balance factor (a) was introduced to balance between the vertical and horizontal forces exerted on the particles.

The main conclusions can be derived from this research is that design of homogenous conical fluidized bed is highly dependent on the design of the arc shape distributor. The angles of the holes in the distributor have to be at the same angle of the bed walls. Also, the thickness of the distributor is crucial in order to provide the inlet gas with sufficient energy to fluidize the particles in the bed. Theoretical, it is possible to create a homogeneous fluidization process using an arc shaped distributor. This can be applied in drying processes where the dried product can be collected from the top while drying in progress due to the difference in particles weights and fluidization velocities. The conical and arc shaped bed and distributor, respectively, can create layers of different fluidization velocities.

\section{Nomenclature}

\begin{tabular}{|c|c|c|}
\hline Notation & Definition & Unit \\
\hline $\mathrm{a}$ & Balance factor & --- \\
\hline A & Arc length of distributor & $\mathrm{m}$ \\
\hline $\mathrm{Ar}$ & Archimedes number & --- \\
\hline $\mathrm{D}_{\mathrm{d}}$ & Distributor diameter & $\mathrm{m}$ \\
\hline $\mathrm{D}_{\mathrm{i}}, \mathrm{D}_{\mathrm{o}}$ & Diameter of conical bed & $\mathrm{m}$ \\
\hline $\mathrm{d}_{\mathrm{pi}}$ & Particle diameter & $\mathrm{m}$ \\
\hline$d_{v}$ & Equivalent particle diameter & $\mathrm{m}$ \\
\hline $\mathrm{F}$ & Force exerted on the particle & $\mathrm{N}$ \\
\hline $\mathrm{g}$ & Gravity acceleration & $\mathrm{m} \mathrm{s}^{-2}$ \\
\hline $\mathrm{K}$ & Increment in column diameter & $\mathrm{m}$ \\
\hline$Q_{0}$ & Gas flow rate & $\mathrm{m}^{3} \mathrm{~s}^{-1}$ \\
\hline $\mathrm{R}$ & Distributor diameter & $\mathrm{m}$ \\
\hline$r_{0}$ & Radius of bas & $\mathrm{m}$ \\
\hline$u_{g}$ & Gas velocity & $\mathrm{m} \mathrm{s}^{-1}$ \\
\hline $\mathrm{U}_{\mathrm{i}}, \mathrm{U}_{\mathrm{o}}$ & Gas velocity, any position, and inlet & $\mathrm{m} \mathrm{s}^{-1}$ \\
\hline $\mathrm{U}_{\mathrm{mf}}$ & Minimum fluidization velocity & $\mathrm{m} \mathrm{s}^{-1}$ \\
\hline $\mathrm{V}_{\mathrm{p}}$ & Particle volume & $\mathrm{m}$ \\
\hline$x$ & Height of distributor at the middle point & $\mathrm{m}$ \\
\hline $\mathrm{Z}$ & Height of bed & $\mathrm{m}$ \\
\hline$\mu$ & Gas viscosity & $\mathrm{kg} \mathrm{m}^{-1} \mathrm{~s}^{-1}$ \\
\hline$\rho_{\mathrm{b}}$ & Bed density & $\mathrm{kg} \mathrm{m}^{-3}$ \\
\hline$\rho_{\mathrm{g}}$ & Gas density & $\mathrm{kg} \mathrm{m}^{-3}$ \\
\hline$\rho_{\mathrm{p}}$ & Particle density & $\mathrm{kg} \mathrm{m}^{-3}$ \\
\hline$\varphi$ & Angle of the distributor with respect to $\mathrm{x}$ axis & $\mathrm{rad}$ \\
\hline$\theta$ & Angle of the conic wall with respect to $y$ axis & $\mathrm{rad}$ \\
\hline
\end{tabular}

\section{References}

Aguado, R., Prieto, R., San José, S. M. J. Álvarez, Olazar, M., \& Bilbao, J. (2005). Defluidization modelling of pyrolysis of plastic in a conical spouted bed reactor. Chemical Eng. and Processing, 44(2), 231-235.

Bi, J., \& Kojima, T. (1996). Prediction of temperature and composition in a jetting fluidized bed coal gasifier. Chemical Engineering Sci., 51(11), 2745-2750. http://dx.doi.org/10.1016/0009-2509(96)00146-7

Bi, J., Luo, C., Aoki, K., Uemiya, S., \& Kojima, T. (1997). A numerical simulation of a jetting fluidized bed coal gasifier. Fuel, 76(4), 285-301. http://dx.doi.org/10.1016/S0016-2361(96)00218-9

Biswal, K. C., Bhowmik, T., and Roy, G. K. (1985). Prediction of minimum fluidization velocity for gas-solid fluidization of regular particles in conical vessels. The Chemical Engineering J., 30(1), 57-62. http://dx.doi.org/10.1016/0300-9467(85)80007-1

Cao, J., Cheng, Z., Fang, Y., Jing, H., Huang, J., and Wang, Y. (2008). Simulation and experimental studies on fluidization properties in a pressurized jetting fluidized bed. Powder Technology, 183(1), 127-132. http://dx.doi.org/10.1016/j.powtec.2007.11.033

Chaplin G., Pugsley, T., and Winters, C. (2005). The S-statistic as an early warning of entrainment in a fluidized bed dryer containing pharmaceutical granule. Powder Technology, 149(2-3), 148-156.

http://dx.doi.org/10.1016/j.powtec.2004.11.002

Chaplin, G., Pugsley, T., \& C. Winters. (2004). Application of chaos analysis to pressure fluctuation data from a fluidized bed dryer containing pharmaceutical granule. Powder Technology, 142(2-3), 110-120. http://dx.doi.org/10.1016/j.powtec.2004.05.001

Dora, D. T. K., Panda, S. R., Mohanty, Y. K., \& Roy, G. K. (2013). Hydrodynamics of gas-solid fluidization of a homogenous ternary mixture in a conical bed: Prediction of bed expansion and bed fluctuation ratios. Particuology, 11,681-688. http://dx.doi.org/10.1016/j.partic.2013.02.009

Ihsan, H. (2004). PhD thesis, Fluidization of Catalytic Reaction of Alkylhalides With Silicon and Separation of The 
Product. University of Technology, Baghdad.

Ihsan, H., Mohammed, T.J., \& Jalhoom, M. (2009). Direct Reaction of Silicon with Ethyl Chloride in Fluidized Bed Reactor. International Journal of Chemical Reactor Engineering, 7(1).

Janvijitsakul, K., \& Kuprianov, V. I. (2008). Similarity and modeling of axial CO and NO concentration profiles in a fluidized-bed combustor (co-)firing biomass fuels. Fuel, 87(8-9), 1574-1584. http://dx.doi.org/10.1016/j.fuel.2007.09.006

Jimenez, T., Turchiuli, C., \& Dumoulin, E. (2006). Particles agglomeration in a conical fluidized bed in relation with air temperature profiles. Chemical Engineering Sci., 61(18), 5954-5961.http://dx.doi.org/10.1016/j.ces.2006.05.007

Kaewklum R., \& Kuprianov, V. I. (2008). Theoretical and experimental study on hydrodynamic characteristics of fluidization in air-sand conical beds. Chemical Engineering Sci., 63(6), 1471-1479. http://dx.doi.org/10.1016/j.ces.2007.11.033

Kuprianov, V. I., Janvijitsakul, K. \& Permchart, W. (2006). Co-firing of sugar cane bagasse with rice husk in a conical fluidized-bed combustor. Fuel, 85(4), 434-442. http://dx.doi.org/10.1016/j.fuel.2005.08.013

Kuprianov, V. I., Permchart, W. \& Janvijitsakul, K. (2005). Fluidized bed combustion of pre-dried Thai bagasse. Fuel Processing Technology, 86(8), 849-860. http://dx.doi.org/10.1016/j.fuproc.2004.09.002

Mele, J., Golobič, I., \& Senegačnik, A. (2013). A method to detect and control fully fluidized conical beds with a wide size distribution of particles in the vicinity of the minimum fluidization velocity. Thermal Science, Online-first (00), 164-164. http://dx.doi.org/10.2298/TSCI130627164M

Olazar, M., Aguado, R., San José, M. J., Álvarez, S., \& Bilbao, J. (2006). Minimum spouting velocity for the pyrolysis of scrap tyres with sand in conical beds. Powder Technology, 165(3), 128-132. http://dx.doi.org/10.1016/j.powtec.2006.03.013

Olazar, M., San José, M. J., Peñas, F. J., Aguayo, A. T., Arandes, J. M., \& J. Bilbao. (1995). A simplified model for gas flow in conical spouted beds. The Chemical Engineering J., 56(2), 19-26. http://dx.doi.org/10.1016/0923-0467(94)02847-4

Permchart, W., \& Kuprianov, V. I. (2004). Emission performance and combustion efficiency of a conical fluidized-bed combustor firing various biomass fuels. Bioresource Technology, 92(1), 83-91. http://dx.doi.org/10.1016/j.biortech.2003.07.005

Pugsley, T., Chaplin, G., \& Khanna, P. ( 2007). Application of advanced techniques to conical lab-scale fluidized bed dryers containing pharmaceutical granule. Trans. Inst. Chem. Eng. Food and Bioproducts Processing, 85(C3), 273-283.

Shan, J., Guobin, C., Fan, M., Yu, B., Jinfu, W., \& Yong. J. (2001). Fluidization of fine particles in conical beds. Powder Technology, 118(3), 271-274. http://dx.doi.org/10.1016/S0032-5910(00)00385-5

Shan, J., Hu, Q., Wang, J., \& Jin, Y. (2000). Fluidization of coarse particles in gas-solid conical beds. Chemical $\begin{array}{llll}\text { Engineering and Processing: } & \text { Process }\end{array}$ http://dx.doi.org/10.1016/S0255-2701(99)00103-8

Singh, R. K., \& Roy, G. K. (2005). Prediction of minimum bubbling velocity, fluidization index and range of particulate fluidization for gas-solid fluidization in cylindrical and non-cylindrical beds. Powder Technology, 159(3), 168-172. http://dx.doi.org/10.1016/j.powtec.2005.08.008

Son, S. Y., Lee, D. H., \& Kim, S. D. (2006). Effect of uniformity of gas distribution on fluidization characteristics in conical gas fluidized beds. Studies in Surface Sci. and Catalysis, 159, 557-560.

Toyohara, H., \& Kawamura, Y. (1992). Fluidization of a tapered fluidized-bed of a binary particle-mixture. Int.Chem.Eng., 33, 164.

Wang, Z. G., Bi, H. T., \& Lim, C. J. (2006). Numerical simulations of hydrodynamic behaviors in conical spouted beds. China Particuology, 4(3-4), 194-203.http://dx.doi.org/10.1016/S1672-2515(07)60261-9

Wen, C. Y., \& Yu. Y. H. (1966). Mechanics of fluidization. Chemical Engineering Progress Symposium Series, 62, $100-111$.

Wiens, J., \& Pugsley, T. (2006). Tomographic imaging of a conical fluidized bed of dry pharmaceutical granule. Powder Technology 169(1), 49-59. http://dx.doi.org/10.1016/j.powtec.2006.07.022

Wormsbecker, M., Adams, A., Pugsley, T., \& Winters, C. (2005). Segregation by size difference in a conical fluidized bed of pharmaceutical granulate. Powder Technology, 153(1), 72-80. 
http://dx.doi.org/10.1016/j.powtec.2005.02.006

Wormsbecker, M., van Ommen, R., Nijenhuis, J., Tanfara, H., \& Pugsley, T. (2009). The influence of vessel geometry on fluidized bed dryer hydrodynamics. Powder Technology 194(1-2), 115-125. http://dx.doi.org/10.1016/j.powtec.2009.03.036

Zhou, D., Dong, S., Wang, H., \& Bi, H. T. (2009) . Minimum fluidization velocity of a three-phase conical fluidized bed in comparison to cylindrical fluidized bed. Ind. Eng. Chem. Res. 48, 27-36. http://dx.doi.org/10.1021/ie8001974

\section{(c) EY}

This work is licensed under a Creative Commons Attribution 3.0 License. 